\title{
Semiannual Kelvin Waves Propagation along the South Coast of Sumatra-Jawa-Bali and the Lesser Sunda Islands Observed by TOPEX/POSEIDON and ERS-1/2 Satellites
}

\author{
F. Syamsudin ${ }^{1}$ \\ ${ }^{1}$ Center for Application and Assessment of Technology for Natural Resources \\ Inventory, Agency for the Assessment and Application of Technology (BPPT), \\ Indonesia.
}

\begin{abstract}
The merged TOPEX/POSEIDON (T/P) and ERS-1/2 altimeter data during 10/14/1993 - 2/12/2002 have been used to study Indian Ocean Kelvin waves propagation along the south coast of Jawa, Bali, Lombok, and the Lesser Sunda Islands. The results show that the occurrence of semiannual Indian Ocean Kelvin waves either in April/May or November/December for all the year of 1993-2001 (except in 1994) with the intraseasonal period and phase speed ranging from 35 to 90 -day and 1.54 to $2.9 \mathrm{~m} / \mathrm{s}$, respectively.
\end{abstract}

Keywords: Indian Ocean Kelvin waves; two-dimensional wave-frequency spectral analysis; phase speed and intraseasonal period.

\section{Background}

Equatorial Kelvin waves, coming from the western equatorial Indian Ocean, impinge on the west coast of Sumatra on the equator and stimulate a reflected Rossby wave back into the Indian Ocean, and northward and southward propagating, coastally trapped Kelvin waves (CTKW's) (Clarke and Liu, 1993;1994). Sprintall et. al. (1999) employed a simple analytical model to predict changes in coastal sea level due to along-shore wind stress by decomposing the momentum equations into vertical modes, and integrating along the path taken by Kelvin wave. They resolved the timing of the event of the incoming Indian Ocean Kelvin wave predicted in the current meter mooring at Cilacap (South Jawa water) match well with the observation.

Figure 1 shows volume transport versus time at the current meter moorings MAK 1 and MAK 2 at the narrowest Labani channel within the Makassar Strait. An interesting event happened when the transport varied from $0 \mathrm{~Sv}$. during the late of May 1997 to over 20 Sv in July 1997. Sprintall et. al. (2000) showed that this event was associated with an Indian Ocean coastally trapped Kelvin wave passing through Lombok Strait before entering Makassar Strait. The Kelvin wave was due to westerly wind forcing in the remote equatorial Indian Ocean during the semi-annual April/May monsoon transition period (Wyrtki, 
1973; Sprintall et. al., 1999; Susanto et. al., 2001). This indicates that the incoming Indian Ocean Kelvin wave enters the internal Indonesian Seas through Lombok Strait and affects the flow in the downstream (poleward) straits. The implication of this evidence complies that Indian Ocean Kelvin waves play an important role on reducing the outflow transport variability of the Indonesian Throughflow (ITF), and further on regional climate change.
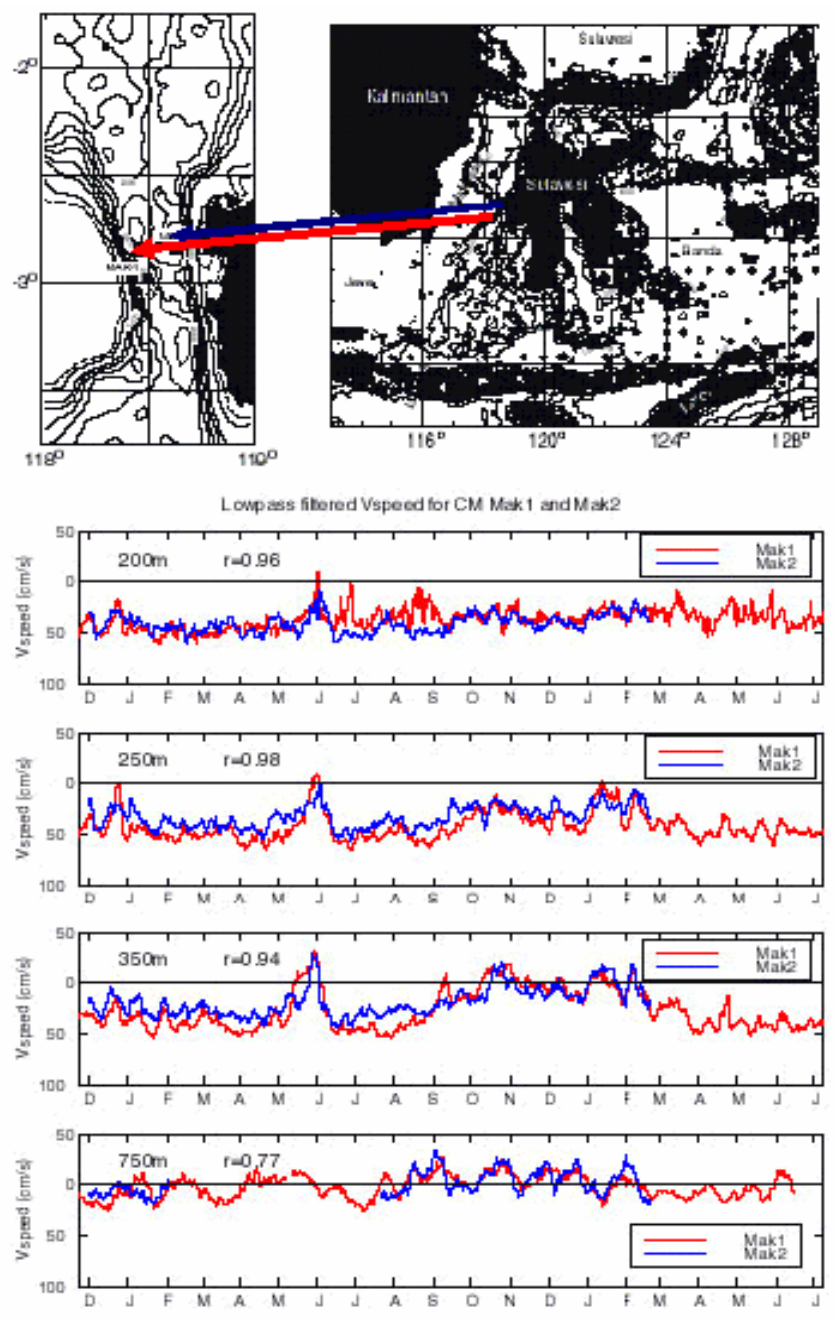

Figure $1 \mathrm{~V}_{\text {speed }}$ in the northward and southward direction of the Indonesian throughflow versus time at the MAK 1 (red line) and MAK 2 (blue line) moorings (see top panel for the locations). The relaxation process happened in the end of May until early June 1997 when the northward velocity against the throughflow, as shown in depth $200 \mathrm{~m}, 250 \mathrm{~m}$, and $350 \mathrm{~m}$. Units of velocity are in $\mathrm{cm} / \mathrm{s}$. (figure modified from Gordon et. al., 1999). 
In this paper, we examine Sea Surface Height Anomaly (SSHA) of the merged TOPEX/POSEIDON (T/P) and ERS-1/2 satellite data during 10/14/1993 2/12/2002 (9.4 years) to clarify occurrence of incoming Indian Ocean Kelvin waves, their phase speed and periodicity along the south coast of Sumatra, Jawa, Bali, and the Lesser Sunda Islands.

\section{Method}

The merged T/P and ERS-1/2 altimeter data were obtained from the Space Oceanography Division of Collecte Localization Satellites (CLS) in Toulouse, France (Le Treon, et. al., 1998). It has spatial intervals of $1 / 3$ degree and with a repeat cycle of 7 days. The data used here are from January 1993 through December 2001 and all T/P data are available for the whole period, except there are no merged T/P and ERS fields between January 1994 and March 1995 (ERS-1 geodetic phase).

In order to observe the occurrence of KW along the south coast of Sumatra, Jawa, Bali and Lesser Sunda Islands, we apply hoevmoller (time-longitude) diagram along-coast transect as shown in the Fig. 2. A frequency-wavenumber spectral analysis technique is performed to detect Kelvin wave signals alongcoast of transect. A dispersion diagram is obtained by performing a twodimensional space and time spectral analysis by removing the linear trend of the SSHA data. Kelvin wave periodicity is performed by theoretical Kelvin wave dispersion curve.

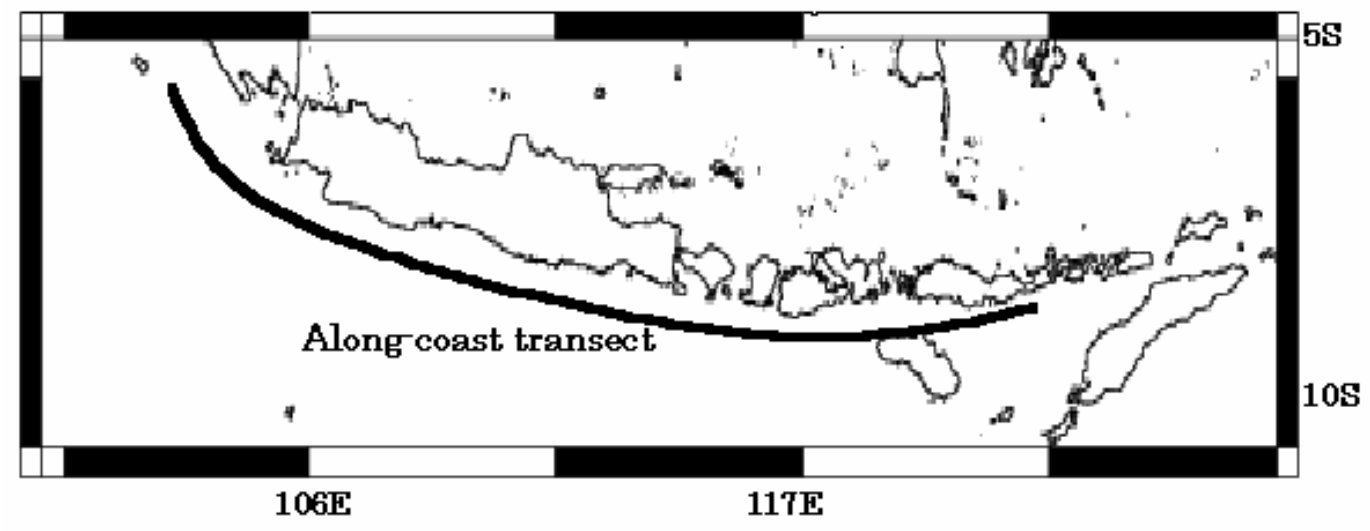

Figure 2 The along-coast transect of Jawa-Bali (JW-BL) and the Lesser Sunda Islands. 


\section{$3 \quad$ Result and Analysis}

Time versus distance or Time-Longitude (Hoevmoller) diagram of SSHA (left panel of Fig. 3) captures semiannual Indian Ocean Kelvin waves seen as a narrow red band along-coast transect (Fig. 2) either in April/May or November/December, except in 1994 where the Kelvin waves do not exist. Center panel of Fig. 3 is the zoom out for the Kelvin wave evidence in the year of 1997. It shows the peak corresponding to the passage of the KW signals that propagate with phase speed ranging from 1.54 to $1.9 \mathrm{~m} / \mathrm{s}$. The inclination of the contours indicates that the Kelvin waves propagate from west to east along transect.
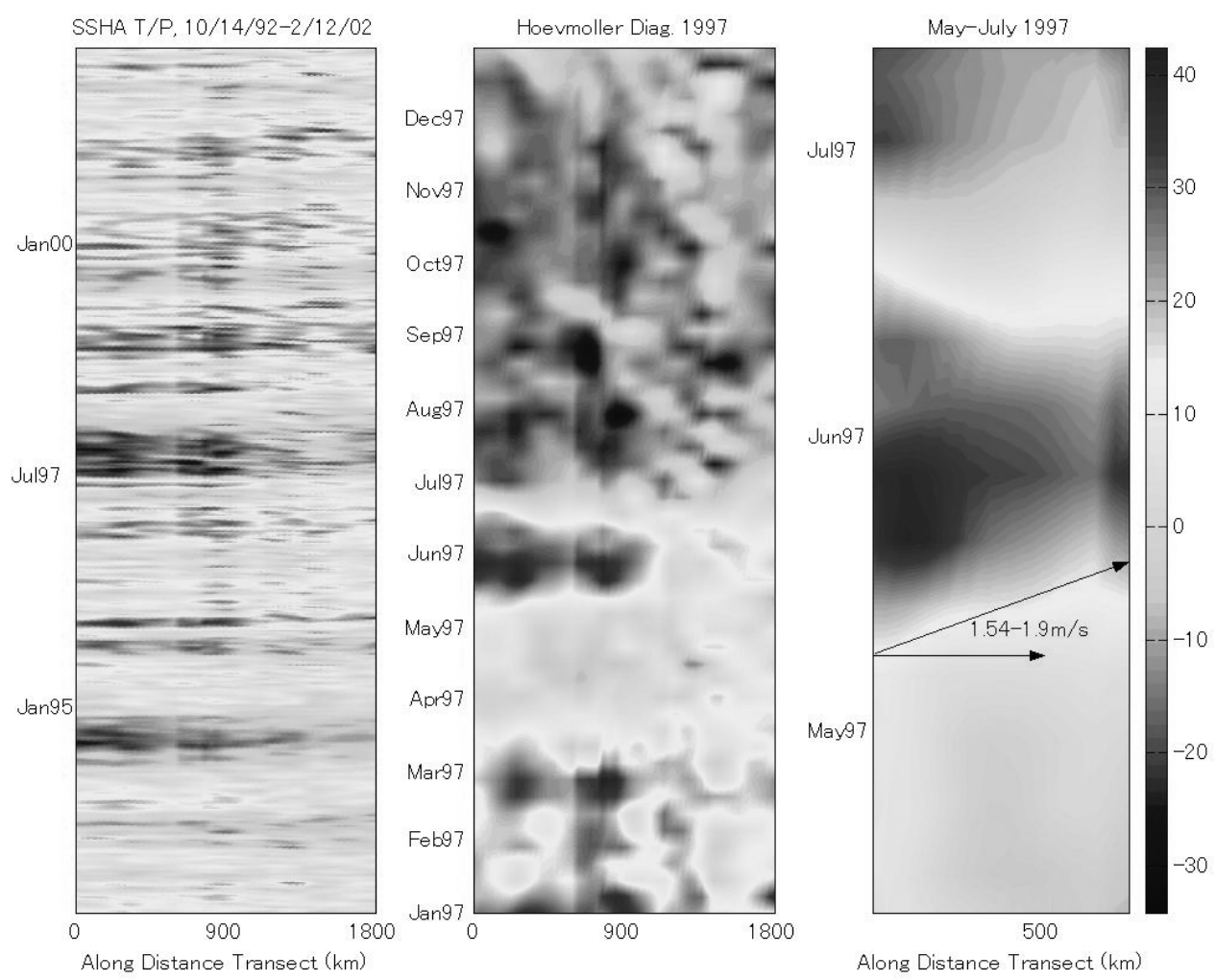

Figure 3 Time-Longitude (hoevmoller) diagram of SSHA during 10/14/93 2/12/02 (left panel), year of 1997 (center panel), and the phase speed calculation of Indian Kelvin Ocean Kelvin waves occurrence around May-June 1997 (right panel). The red narrow bands on the panels are the Kelvin wave signal occurrences. The scale bars are in $\mathrm{cm}$. 
Fig. 4 presents a dispersion plot for all the year data of the Kelvin waves variance (power spectral density) signals along-coast transect. A dispersion diagram is obtained by removing the linear trend of the SSHA and performing a two-dimensional spectral analysis. The power contours are dominated by two frequency-wavenumber responses whose $\omega / \mathrm{f}$ and $\mathrm{k} * \mathrm{R}$ are ranging from 0.0125 to 0.0225 and 0 . (Here $\omega / \mathrm{f}$ and $\mathrm{k}^{*} \mathrm{R}$ are non-dimensional frequency and wavenumber where $f$ is the reference Coriolis frequency; $\omega$ the wave frequency; $\mathrm{k}$ the along-transect wave number; and $\mathrm{R}$ the Rossby radius of deformation). The $\omega / f$, frequencies correspond with the power contours peak within intraseasonal period of $\mathrm{KW}$ ranging from 30 to 90 days as confirmed by the straight line of the theoretical Kelvin wave dispersion curve. The zero wavenumber is an artifact of the wave generation mechanism and the signature of natural scale for trapped waves.

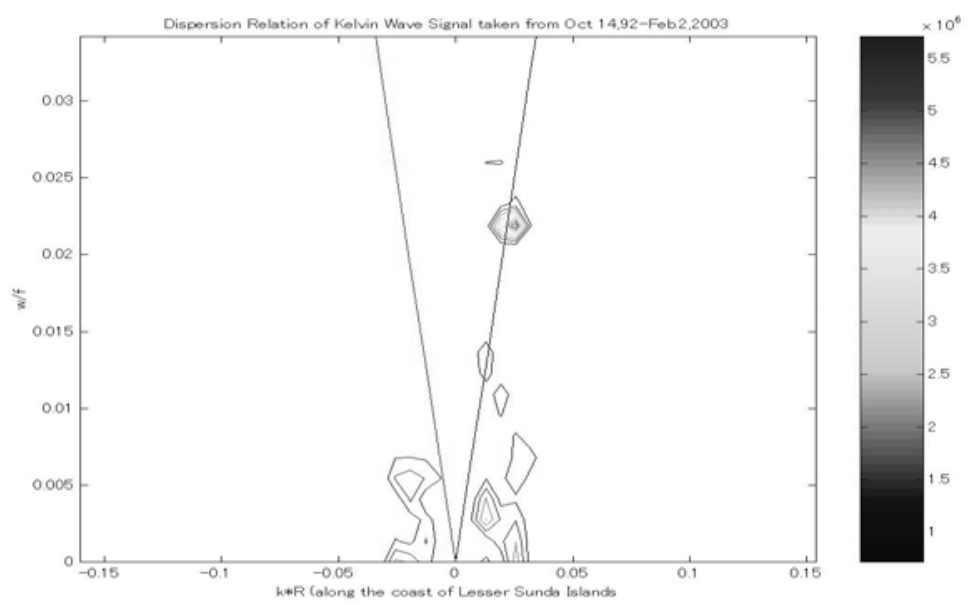

Figure 4 Dispersion plot of Variance of Indian Ocean Kelvin waves signals during $10 / 14 / 93-2 / 12 / 02$. The black straight line is the theoretical Kelvin wave dispersion curve. The scale bars are in $\mathrm{m}^{2}$.

In order to confirm the existence of Indian Ocean Kelvin waves in this region, we employ a complete analysis to detect those signals with the spectral analysis within annual basis. Fig. 5 presents 4 of 10 years data analysis of T/P and ERS1/2 SSHA. Same analysis for the year of 1996, 1998, 1999, 2000, and 2001 is not shown in the figure.

There is no indicative of Kelvin wave signal in the year 1994 as previously analyzed by the hovmoller diagram in the Fig. 3 (left panel). The $\omega / \mathrm{f}$, frequencies still correspond with the power contours peak within intraseasonal period of KW ranging from 30 to 90 days separated by two dominant intraseasonal periods of $30-40$ and 50-90 days with the shorter scale has more 
intense and stronger signal. The phase speed for all year data analysis is within $1.54-2.9 \mathrm{~m} / \mathrm{s}$. The broad range of phase speed is indicative of strong modulation of interannual and intraseasonal variations of wind and MaddenJulian oscillation, respectively, in this region as well as seasonal reversing South Java current variability along the southern coast of Jawa.

This evidence implies that semiannual upstream Kelvin wave propagation in this region will have a significant effect on relaxing and reversing the southward Lombok and Ombai straits throughflow for several days (Syamsudin et. al, 2004). Presumably the Indian Ocean water must eventually return to the Indian Ocean. If so, the returned flow into the Indian Ocean may not be at the same depth, and water mass characteristics may have changed due to mixing processes and sea-air fluxes in the internal Indonesian Seas. This would influence the salt and heat budget transport to the Indian Ocean and consequently regional climate changes. Further analysis on this issue will be our upcoming paper analysis.
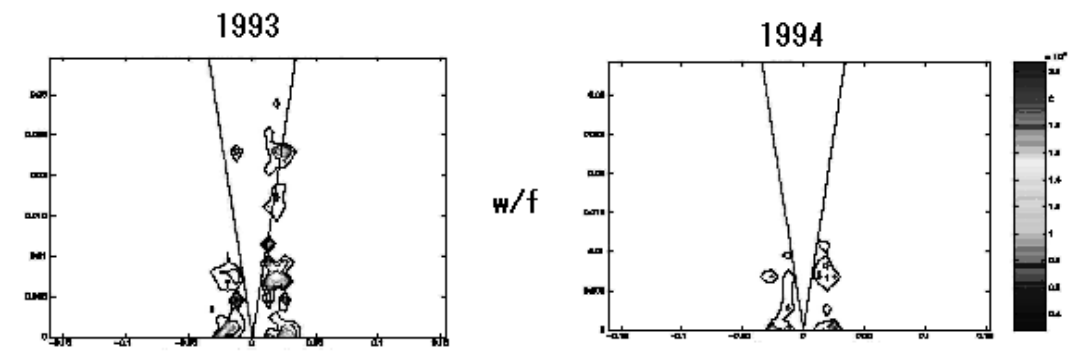

1995
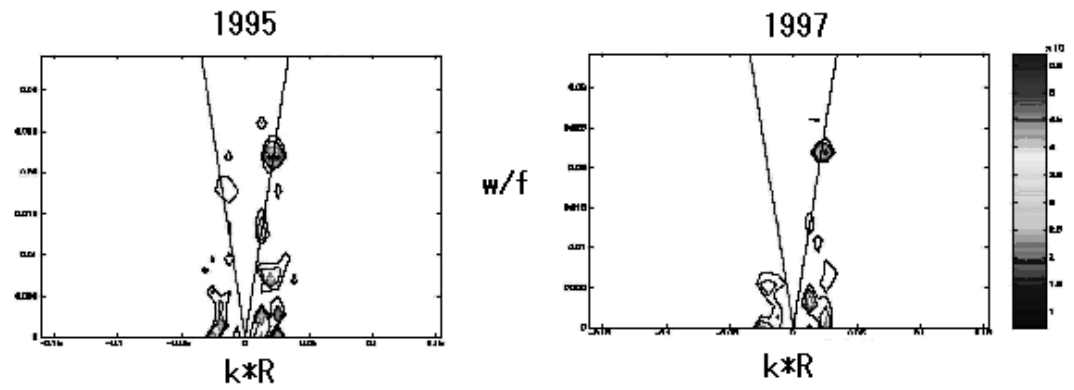

Figure 5 Dispersion diagram for the year of 1993, 1994, 1995, and 1997. The scale bars indicating variance (power spectral density) of Sea Surface Height Anomaly (SSHA) in $\mathrm{m}^{2}$.

Future work will be interesting to understand how do Indian Ocean Kelvin wave intensities change within regional climate change such as ENSO and Indian Ocean Dipole in this Indo-Australian Bight and how much energy exchange through Lombok Strait. 


\section{Conclusion}

The semiannual and coastally trapped of Indian Ocean Kelvin waves propagate along the south coast of Jawa, Bali, Lombok, and the Lesser Sunda Islands. They exist either in April/May or November/December for all the year of 19932001 (except in 1994) with the intraseasonal period and phase speed ranging from 35 to 90 -day and 1.54 to $2.9 \mathrm{~m} / \mathrm{s}$, respectively.

\section{Acknowledgements}

We thank two anonymous reviewers for constructive comments. The CLS Space Oceanography Division supplied the merged T/P and ERS-1/2 data.

\section{References}

1. Clarke, A. J., On the Reflection and Transmission of Low-Frequency Energy at the Irregular Western Pacific Ocean Boundary, J. Geophys. Res., 96, pp. 53289-3305 (1991).

2. Clarke, A. J. \& Liu, X., Observation and Dynamic of Semi-Annual and Annual Sea Levels Near the Eastern Equatorial Indian Ocean Boundary, J. Phys. Oceanogr., 23, pp. 386-399 (1993).

3. Sprintal, J., Chong, J. C., Syamsudin, F., Morawit, W., Hautala, S., Bray, N. \& Wijffels, S., Dynamics of the South Java Current in the IndoAustralian Basin, Geoph. Res. Lett., 26, pp. 2493-2496 (1999).

4. Sprintal, J., Gordon, A. L., Martugudde, R., \& Susanto, R. D., A Semiannual Indian Ocean Forced Kelvin Wave Observed in The Indonesian Seas in May 1997, J. Geophys. Res., 105, pp. 17,217- 17,230 (2000).

5. Wyrtki, K., An Equatorial Jet in The Indian Ocean, Science, 181, pp. 262-264 (1973).

6. Susanto, R. D., Gordon, A. L. \& Zheng, Q., Upwelling Along the Coasts of Java and Sumatra, Indonesia, Geophys. Res. Lett., 28, pp. 1599-1602 (2001).

7. Gordon, A. L., Susanto, R. D. \& Ffield, A., Throughflow Within Makassar Strait, Geophysical Research Letters, 26, pp. 3325-3328 (1999).

8. Le Traon, P. Y., Nadal, F. \& Ducet, N., An Improved Mapping Method of Multisatellite Altimeter Data, J. Atmost. Oceanic Technol., 15, pp. 522533 (1998).

9. Syamsudin, F., Kaneko, A. \& Haidvogel, Dale B., Numerical and Observation Estimates of Indian Ocean Kelvin Wave Intrusion into Lombok Strait, Geophys. Res. Lett. (In press). 